\title{
RS-BASED WATER RESOURCES INVENTORY OF THE PHILIPPINES: CAPACITY BUILDING EFFORTS FOR NATIONWIDE IMPLEMENTATION
}

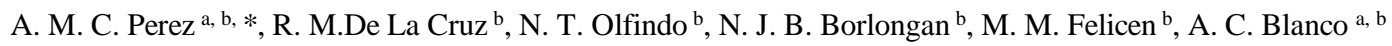 \\ ${ }^{a}$ Department of Geodetic Engineering, University of the Philippines, Diliman, Quezon City, Philippines 1101 - \\ (anjillyn_mae.cruz, ariel.blanco)@upd.edu.ph \\ ${ }^{\mathrm{b}}$ Phil-LiDAR 2 Program, Training Center for Applied Geodesy and Photogrammetry, University of the Philippines, Diliman, Quezon \\ City, Philippines 1101 - (rmdelacruz.phillidar2.upd, ntolfindojr.phillidar2.upd, njbborlongan.phillidar2.upd, \\ mmfelicen.phillidar2.upd)@gmail.com
}

Commission VI, WG VI/6

KEY WORDS: Capacity Building, Hydrologic Data, Geodatabase, Water Resource Inventory, Water Resource Mapping, LIDAR

\begin{abstract}
:
Considering that the Philippines is archipelagic in nature and is exposed to disasters accentuated by climate change, water resource monitoring and management has been an important concern in the country. The design and implementation of an effective management scheme relies heavily on accurate, complete, and updated water resource inventories, usually in the form of maps and geodatabases. With the aim of developing a detailed and comprehensive database of all water resources in the Philippines, a 3-year project entitled "Development of the Philippine Hydrologic Dataset (PHD) for Watersheds from LiDAR Surveys", has been initiated by the University of the Philippines Diliman (UPD) and the Department of Science and Technology (DOST). Various workflows has been developed to extract inland hydrologic features in the Philippines using accurate Light Detection and Ranging (LiDAR) Digital Terrain Models (DTMs) and LiDAR point cloud data obtained through other government-funded programs, supplemented with other remotely-sensed imageries and ancillary information. Since the project covers national-scale mapping and inventory, the implementation was structured to be a collaborative effort between fifteen (15) State Universities/Colleges (SUCs) and Higher Education Institutes (HEIs), along with multiple National Government Agencies (NGAs) and Local Government Units (LGUs). This paper presents the project's general structure, focusing mainly on its attempts and accomplishments in strengthening individual capacities of all involved SUCs, HEIs, and stakeholders utilizing hydrologic data for different applications.
\end{abstract}

\section{INTRODUCTION}

\subsection{Water Resources in the Philippines}

Water resources inventory, monitoring, and management is an important concern in the Philippines. This is due to the country's archipelagic setting, making it enriched with a wide variety of natural and man-made water resources which has high vulnerability to disasters imposed by the global effects of climate change. According to the National Water Resources Board (NWRB), there are 421 principal river basins in the country with catchment areas ranging from 40 to 25,469 square kilometers, and 18 of which are considered as major river basins (DPWH \& JICA, 2003). These basins are composed of water channels in the form of streams and irrigation networks stretching to hundreds of kilometers throughout the nation, as well as terrestrial water bodies of varying spatial coverage including wetlands, lakes, marshes, swamps, reservoirs, and ponds, among others. Maps of these resources in various parts of the country are available; however, the water features are presently not up-to-date.

Having this vast amount of water resources, the first step in proper water management is knowing the extent and state of all available resources. A detailed and accurate water resources inventory is deemed necessary to ensure that proper management is executed to promote better sustainability.

\subsection{The PHD Project}

As an initial step to address the general need for the inventory of different resources in the Philippines, the 3-year Phil-LiDAR 2 Program, focused on "Detailed National Resources Assessment", has commenced on July 2014. The research was spearheaded by the Training Center for Applied Geodesy and Photogrammetry (TCAGP) of the University of the Philippines Diliman (UPD), and funded by the Department of Science and Technology (DOST). The program involves research collaboration between 15 State Universities/Colleges (SUCs) and Higher Education Institutes (HEIs), along with various National Government Agencies (NGAs) and Local Government Units (LGUs).

One of the projects under this program is the "Development of the Philippines Hydrologic Datasets (PHD) for Watersheds from LiDAR Surveys" which mainly aims to develop a national repository of hydrologic datasets for the country using data derived from Light Detection and Ranging (LiDAR) surveys. Specifically, the project's objectives are: (1) develop workflows to generate different hydrologic datasets; (2) create detailed maps of water resources extracted from LiDAR and other RS datasets; and (3) produce a geodatabase of different hydrologic features which can be used for various applications. A total of 13 out of 15 SUCs/HEIs (Table 1) committed to perform tasks needed to accomplish the objectives of the PHD Project, including UPD.

* Corresponding author 


\subsection{Project Structure and Components}

The project's general workflow is shown in Figure 1. The UPD's major role in the project involves the development of the workflows and capacity building. Since PHD is a collaborative project, developments on the extraction methods are efficiently communicated to partner SUCs/HEIs and NGAs through trainings and mentoring sessions. The SUCs/HEIs implement the developed workflows and/or perform field validation (FV) and accuracy assessment (Table 1) for the river basins (RBs) assigned to each of them. There are $285 \mathrm{RBs}$ targeted by the project. The coverage of each SUC/HEI can be seen in Figure 2, where the outlined features are major RBs assigned to UPD. All RBs not processed or validated by partner SUCs/HEIs are handled by UPD as well. Outputs from data processing (DP) and field data gathering are then subjected to intensive quality assurance and control (QA/QC) performed by UPD to ensure the reliability of data that will be added in the geodatabase for proper archiving and distribution. Concurrent with documentation, processing, field validation, QA/QC, and capacity building efforts of UPD, policy reviews are also being performed in order to formulate necessary policy recommendations that may help address future water resource management issues in the Philippines.

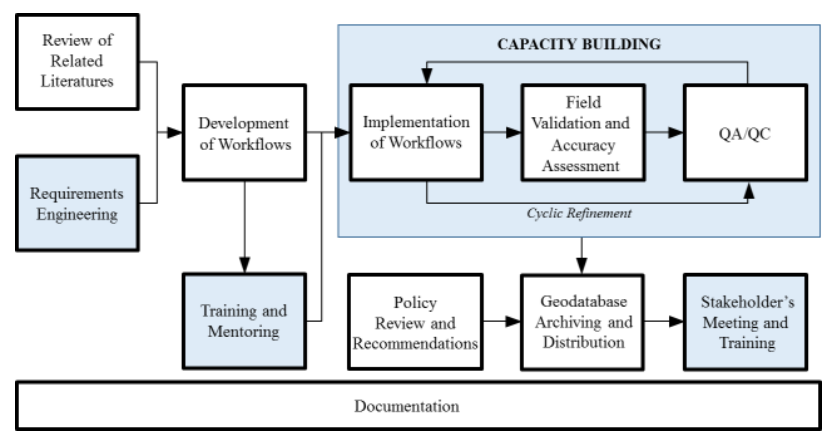

Figure 2. The PHD Project's general workflow

\begin{tabular}{|l|c|c|c|}
\hline \multirow{2}{*}{ SUC/HEI } & No. & \multicolumn{2}{|c|}{ Tasks } \\
\cline { 3 - 4 } & RBs & DP & FV \\
\hline Ateneo de Naga University (ADNU) & 29 & 0 & 29 \\
Central Luzon State University (CLSU) & 8 & 8 & 8 \\
Central Mindanao University (CMU) & 5 & 5 & 5 \\
Caraga State University (CSU) & 13 & 13 & 13 \\
Isabela State University (ISU) & 8 & 8 & 8 \\
Mapua Institute of Technology (MIT) & 27 & 27 & 27 \\
Mariano Marcos State University (MMSU) & 15 & 15 & 15 \\
Mindanao State Univ.- Iligan IT (MSU-IIT) & 11 & 11 & 11 \\
University of San Carlos (USC) & 17 & 17 & 17 \\
University of the Phils. Diliman (UPD) & 63 & 140 & 91 \\
University of the Phils. Cebu (UPCebu) & 26 & 10 & 10 \\
University of the Phils. Mindanao (UPMin) & 20 & 0 & 20 \\
Visayas State University (VSU) & 31 & 31 & 31 \\
\hline
\end{tabular}

Table 1. List of SUCs/HEIs, number of RBs, and PHD tasks

Since the project involves inventory and mapping of water resources in a national scope, it was divided into three (3) subcomponents based on the nature of the features. The subcomponents of PHD are: (1) delineation of stream channels; (2) extraction of inland wetlands; and (3) compilation and extraction of irrigation networks. The sub-components are focused on the mapping of different hydrologic units from RS images using combinations of different RS and GIS methods.

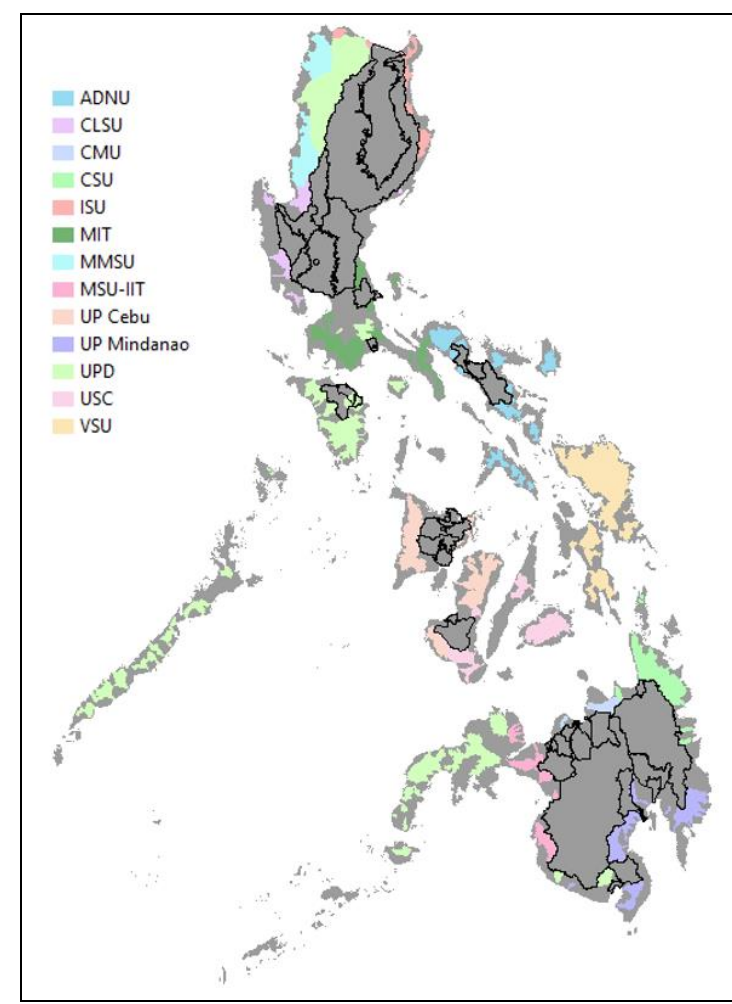

Figure 2. Map of assigned RBs per SUC/HEI

\section{RS-BASED WATER RESOURCE INVENTORY}

\subsection{Water Resources Mapping Methods}

With the recently available LiDAR data and other remotelysensed images in the country from various research efforts of the government, the nationwide assessment and mapping of water resources becomes more feasible. Digital Terrain Models (DTMs) with 1-meter spatial resolution derived from LiDAR point cloud data acquired and pre-processed by the Disaster Risk and Exposure Assessment for Mitigation (DREAM) Program are the primary dataset utilized in this project. Other images and essential ancillary data used in implementing the different feature extraction workflows, accuracy assessment, and geodatabase development include SAR DTMs, orthophotos, WorldView-2 images, Landsat images, irrigation and topographic maps, and field survey data, among others. The processing workflows per component are briefly discussed in the following sub-topics.

2.1.1 Streams and Watersheds: The first sub-component of PHD deals with streams and watershed delineation. Streams are channels characterized by a continuous flow wherein the flow direction can be determined by analyzing the topography of the area. Watersheds are those areas comprised of a network of stream channels and other hydrologic bodies where surface water drains into. The methods involved for watershed and stream delineation include: (1) pre-processing of LiDAR-derived DTM images by hydrologic conditioning (e.g. removal of bridges) and sink filling; (2) iterative flow direction, flow accumulation, stream definition, stream segmentation, and drainage line processing using the ArcHydro tool in ArcGIS® and Flow Path Tracing (FPT); (3) delineation of catchments and watersheds; and (4) field validation and accuracy assessment. Figure 3 shows the catchments and streams delineated in a portion of Panay RB. 


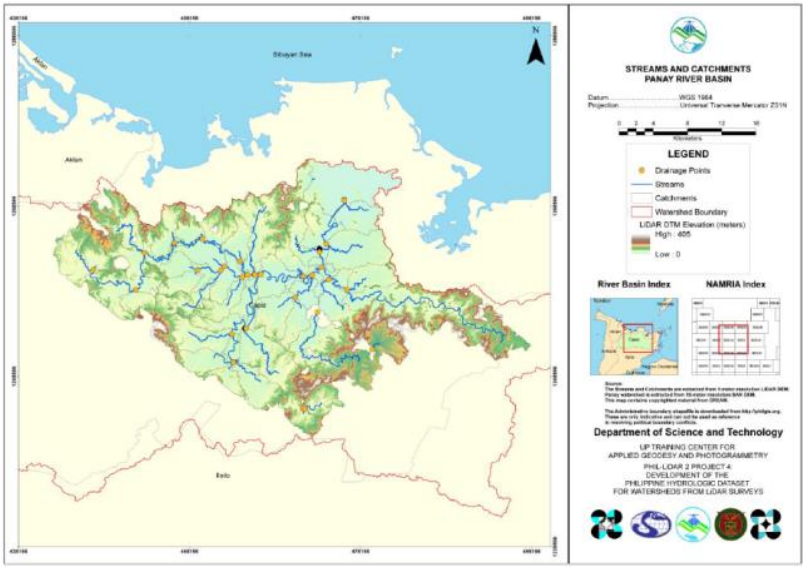

Figure 3. Delineated catchments and stream networks in a portion of Panay River Basin

2.1.2 Inland Wetlands: The second sub-component of PHD is concerned with inland wetland extraction. Wetlands are defined by Sharma et al. (2010) as "those areas that are inundated or saturated by surface or ground water at a frequency and duration to support and under normal circumstances do support, a prevalence of vegetation typically adapted for life in saturated soil conditions". The major method used in delineating inland wetlands is the Stochastic Depression Analysis (SDA) using high resolution LiDAR DTM. The results are subjected to multiple filtering processes, field validation, and accuracy assessment before being uploaded for archiving and distribution.

2.1.3 Irrigation Networks: The last sub-component of PHD involves the mapping of irrigation ditches and canals necessary to supply water in agricultural fields. Irrigation systems consist of man-made structures responsible for supplying water in agricultural areas to increase yield and maintain a stable temperature of crops (Rapinel et al., 2013). The methodology designed to extract irrigation canals and ditches of varying widths from LiDAR DTMs involves the use of various GIS tools in $\operatorname{ArcGIS}{ }^{\circledR}$ and Whitebox, as presented in Figure 4. The parameters used in deriving the Map Gully Depth layer, vectorization, and filtering are also presented in Figure 4.

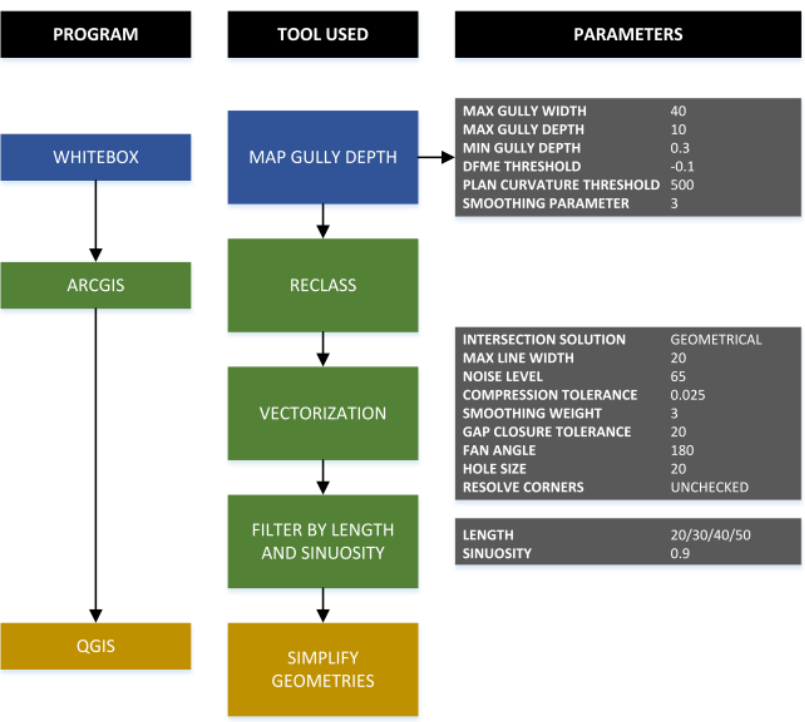

Figure 4. Irrigation network extraction workflow

\section{CAPACITY BUILDING EFFORTS AND ACCOMPLISHMENTS OF THE PHD PROJECT}

In general, national capacity building encompasses the strengthening of each country's human, scientific, technological, organizational, institutional, and resource capabilities (UNEP, 2002). According to Samarakoon et al. (2008), capacity building activities are usually carried out for most of developing countries within national sponsorship (e.g. part of funded projects). This is commonly achieved by funding research projects with a capacity building component, as with the case of the Phil-LiDAR 2 Program. However, overcoming problems to enhance capacity in a national scale is usually difficult since it requires a major change in the attitude and practices of individuals and implementing institutions (Samarakoon et al., 2008).

The summary of capacity building efforts and accomplishments of the PHD project from the start of the program in July 2014 until March 2016 are presented in the succeeding sections.

\subsection{Efforts for Nationwide Capacity Building}

Aside from the development of the workflows, processing, validation, and quality checking, another major role of UPD in the implementation of the PHD project is to implement capacity building involving the collaborating SUCs/HEIs, NGAs, and LGUs. To implement the mapping and inventory of water resources in a national scale, it is necessary to produce sufficient number of trained personnel that are equipped with the technical knowledge and management skills needed in order to ensure the timely delivery of the outputs that are within the accepted quality standards. To achieve this, various capacity building efforts has been implemented by the project.

3.1.1 Process Trainings: These are done by gathering representatives from all collaborating SUCs/HEIs to undergo a 4-day training including lectures, hands-on data processing, field validation simulation activities, and consultative meetings. The lectures usually focuses on the concepts behind the processing being implemented. The hands-on data processing helps the trainees to be equipped with the proper technical skills and resourcefulness. Errors or problems that may be encountered during actual processing of the participants' assigned RBs are also addressed in this activity. Field simulation is done to train the personnel on how to use the field devices such as hand-held GPS and rangefinders to obtain the necessary data. This also enable them to be familiar with the proper protocols that should be exercised in the grounds. Consultative meetings give avenue for the trainees to plan and schedule their own activities with the guidance of the PHD research team.

3.1.2 Mentoring: The activities involved in mentoring are quite similar to the process trainings, except that the SUCs/HEIs are trained separately in their respective universities and institutes. The PHD team delivers the series of lectures, hands-on exercises, field validation, and meetings in a 5-day period. Actual data of RBs assigned per SUC/HEI may be processed if available. Field validation in the nearest assigned RB or within the vicinity of the training venue is also conducted with the proper coordination with the LGUs. This practice is important to ensure the safety of the personnel. Concerns regarding the project are also coordinated to the UPD team for proper and timely action. 
3.1.3 Monitoring: After the series of process trainings and mentoring, the PHD team from UPD performs quarterly monitoring in each cooperating SUC/HEI. Such 2- or 3-day monitoring aims to assess the progress of the project for each university or institute, as well as the performance of the assigned personnel in their actual working environment. Aside from the physical monitoring, on-line monitoring is also done thru the use of a commercial project management software (i.e. Zoho Projects $\left.{ }^{\circledR}\right)$ where deliverables, schedules, activities, and milestones can be presented and assessed easily. PHD research associates in UPD were assigned SUCs/HEIs that they would monitor in a weekly basis. This practice makes sure that all problems are raised and solutions are delivered efficiently.

3.1.4 Joint Fieldworks: Joint fieldworks can be conducted, either on separate dates or during mentoring/monitoring sessions, on actual RBs that need to be validated. The preparations (e.g. processing and field planning) for joint fieldworks can either be handled by UPD PHD team with the help of the SUC/HEI assigned once they arrive in the area, or be handled by the assigned SUC/HEI with the assistance and supervision from the UPD team on the first to second day of field activity.

3.1.5 Echo Trainings: Usually, only some representatives from the SUCs/HEIs attend the process trainings and mentoring activities due to limitations in time and budget constraints. In order to make sure that more people are trained technically with the workflows implemented in the project, echo trainings are done by the SUCs/HEIs with their respective project teammates, not necessarily involved in PHD. The team from UPD also conducts echo trainings for collaborating NGAs concerned with the use of water resources inventories.

3.1.6 Stakeholders' Meetings and formation of a Technical Working Group (TWG): A primary step in the general workflow of the PHD Project is the Requirements Engineering and the most essential part of this process is the Stakeholders' Meeting. All government agencies that require hydrologic datasets for planning and decision making purposes were identified and gathered in an initial Stakeholders' Meeting. The main objective of this activity is to collect necessary inputs from the target users of the water resources inventory, in terms of what features and attributes are important to be included in the geodatabase. Also, a Technical Working Group (TWG) was created and represented by different stakeholders. Members of this TWG serve as consultants of the PHD team whenever there are concerns or issues pertaining to the mapping and use of water resources.

\subsection{Capacity Building Accomplishments}

To date, 34 capacity building activities involving a total of 270 people (i.e. not unique individuals) has been accomplished by the PHD project. This does not include program-wide trainings, colloquiums, and forums organized by Phil-LiDAR 2 Program.

3.2.1 Process Trainings: Two (2) major Process Trainings has been conducted by the UPD PHD team. These two batches arose because the participation and commitment of the SUCs/HEIs were divided in two groups - one committed to perform tasks under PHD from the beginning of the project and the other one just at the start of the program's third year of implementation. The summary is presented in Table 2.

\begin{tabular}{|l|c|c|}
\hline SUCs/HEIs & Date/s & No. of Participants \\
\hline CLSU & & \\
ISU & & \\
MMSU & & \\
MSU-IIT & Aug. 25-28,2015 \\
UP Cebu & & \\
UP Mindanao & & \\
USC & & \\
\hline ADNU & & \\
CMU & Feb. 2-5, 2016 & 19 \\
CSU & & \\
MIT & & \\
VSU & & \\
\hline
\end{tabular}

Table 2. Process Trainings conducted by PHD

3.2.2 Mentoring: There were six (6) mentoring sessions done covering the first seven (7) SUCs/HEIs who committed to the PHD project. All occurred on the last quarter of 2014 to the first quarter of 2015, before the first Process Training (Table 3).

\begin{tabular}{|l|c|c|}
\hline SUCs/HEIs & Date/s & No. of Participants \\
\hline MSU-IIT & Nov. 29 - Dec. 6, 2014 & 11 \\
\hline MMSU & Feb. 2 - 6, 2015 & 15 \\
\hline CLSU & Feb. 9- 13, 2015 & 7 \\
\hline ISU & Feb. 9- 13, 2015 & 10 \\
\hline $\begin{array}{l}\text { USC } \\
\begin{array}{l}\text { UP Cebu } \\
\text { UP Visayas* }\end{array}\end{array}$ & Feb. 16 - 20, 2015 & 14 \\
\hline UP Mindanao & Mar. 2 - 6, 2015 & 10 \\
\hline
\end{tabular}

Table 3. Mentoring sessions conducted by PHD

Representatives from the *University of the Philippines Visayas attended the training even though the university is not an official part of the program.

3.2.3 Monitoring: There were 14 rounds of monitoring of trained personnel for processing and validation that has been performed by the PHD team, mainly covering the first group of SUCs/HEIs. The team will start the monitoring of the second group of SUCs/HEIs this April 2016. Constant on-line monitoring has also been implemented on a weekly basis for all involved SUCs/HEIs and close coordination between the monitors and each SUCs/HEIs' focal persons has already been established.

\begin{tabular}{|l|c|c|}
\hline SUCs/HEIs & Date/s & No. of Participants \\
\hline MSU-IIT & Nov. 3 - 6, 2015 & 3 \\
\hline ISU & Nov. 3 - 6, 2015 & 2 \\
\hline USC & Nov. 3 - 6, 2015 & 2 \\
\hline UP Cebu & Nov. 3 - 6, 2015 & 3 \\
\hline CLSU & Nov. 3 - 6, 2015 & 3 \\
\hline UP Mindanao & Nov. 3 - 6, 2015 & 2 \\
\hline MMSU & Nov. 3 - 6, 2015 & 6 \\
\hline $\begin{array}{l}\text { USC } \\
\text { UP Cebu }\end{array}$ & Feb. 15 - 17, 2016 & 30 \\
\hline MMSU & Mar. 21 - 23, 2016 & 6 \\
\hline UP Cebu & Mar. 21 - 23, 2016 & 2 \\
\hline USC & Mar. 21 - 23, 2016 & 5 \\
\hline CLSU & Mar. 21 - 23, 2016 & 3 \\
\hline ISU & Mar. 21 - 23, 2016 & 3 \\
\hline MSU-IIT & Mar. 28 - 30, 2016 & 2 \\
\hline
\end{tabular}

Table 4. Mentoring sessions conducted by PHD 
3.2.4 Joint Fieldworks: The summary of field validation activities conducted jointly by UPD and various SUCs/HEIs is presented in Table 5. The joint validation of UPD and CLSU in an irrigation canal is shown in Figure 5.

\begin{tabular}{|l|c|c|}
\hline SUCs/HEIs & Date/s & No. of Participants \\
\hline CLSU & Mar. 23 - 25, 2015 & 3 \\
\hline CLSU & Apr. 27 - 30,2015 & 3 \\
\hline MSU-IIT & Apr. 27 - 30, 2015 & 3 \\
\hline MSU-IIT & May 11 - 22, 2015 & 3 \\
\hline UP Cebu & Sept. 1 - 11, 2015 & 3 \\
\hline CLSU & Oct. 12 -16, 2015 & 3 \\
\hline UP Mindanao & Mar. 27 - 30, 2016 & 2 \\
\hline
\end{tabular}

Table 5. Joint fieldworks conducted by PHD

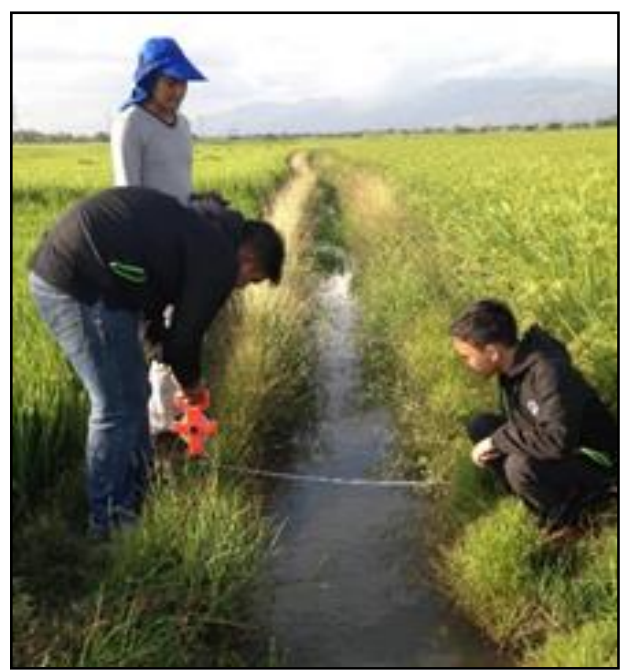

Figure 6. Joint field validation of CLSU and UPD

3.2.5 Echo Trainings: In total, four (4) SUCs/HEIs has conducted echo trainings in their respective offices after the process trainings and mentoring sessions. The topics covered are shown in Table 6.

\begin{tabular}{|l|c|c|}
\hline SUCs/HEIs & Topics & No. of Participants \\
\hline ADNU & Field Validation & 5 \\
\hline CLSU & Processing Workflow & 2 \\
\hline UP Cebu & Processing Workflow & 4 \\
\hline VSU & Stream Extraction & 4 \\
\hline
\end{tabular}

Table 6. Joint fieldworks conducted by PHD

3.2.6 Stakeholders' Meeting: A Stakeholders' Meeting was conducted in April 2015, with 60 participants (Figure 7) from 23 SUCs/HEIs and government entities. The requirements of each agency in terms of hydrologic datasets has also been collated and the TWG was successfully established.

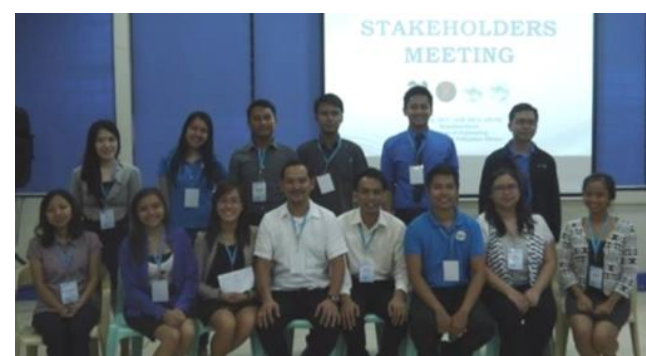

Figure 7. UPD PHD team at the Stakeholders' Meeting in 2015

\section{FUTURE ACTIVITIES}

The task of developing a geodatabase of hydrologic datasets in a national scale is quite challenging because of the magnitude of spatial and non-spatial data that needs to be standardized and compiled, as well as the numerous stakeholders involved with varying data needs and requirements. Despite encountering some issues, the first two years of the PHD Project has been a success with the workflows and guidelines already finalized, refined, and imparted to partner SUCs/HEIs.

Since the PHD Project is still on-going and will end on June 2017, continuous efforts on capacity building are still being implemented and planned to ensure that the knowledge and skills transfer, not only to the researchers of the collaborating SUCs/HEIs but to the personnel in different stakeholders as well, will be successful towards the completion of the nationwide water resources inventory of the Philippines.

\subsection{Sustaining the Capacity}

Constant updating of the initial water resources inventory is necessary to ensure the sustainability of efficient national resource management practices. With this, continuous trainings are necessary to meet-up with the advancing technology and increasing amount of information that can be derived from RS data. Aside from the previously discussed means of capacity building, long-term activities that are deemed necessary as future activities are presented in the subsequent sections.

4.1.1 Training Courses: Since the project is being implemented under the UP TCAGP, the training arm of the UP Department of Geodetic Engineering (UP DGE), it would be easy to conduct follow-up trainings on the updating of the water resources inventory and other applications. Currently, UPTCAGP is offering month-long courses in Remote Sensing and GIS open for government employees from relevant divisions in LGUs and NGAs. Special trainings may also be arranged to cover topics related to the use of geomatics in sustainable water resource management. Researchers, lecturers, and faculty members from different academic institutions will be highly encouraged to undergo the training courses.

4.1.2 Stakeholders' Capacity Building: Before the end of the program, another Stakeholders' Meeting will be organized to report to the partner agencies the outcomes of the project. Aside from this, major stakeholders will be encouraged to host trainings. Interested stakeholders can request for in-house training in their respective offices as well. Even after the completion of project, the inter-agency collaboration will still be maintained by UPD to promote more projects relevant to the development of the country.

4.1.3 Capacitating the Local Units and Technical Assistance from Academic Institutions: The sustainability of water resources inventory and management lies in the hands of the local government units since they have the administrative authority in these resources. Capacitating the LGUs should be prioritized to be able to maximize the use of all hydrologic datasets generated and ensure their proper utilization. Updating of the geodatabase could also be efficiently handled by local personnel since they are the ones living near these resources, as long as they are equipped with the required knowledge and skills. 
To capacitate the LGUs, academic institutions in different provinces and localities must also offer RS and GIS trainings for government personnel, similar to the structure of TCAGP. Although it was discussed that TCAGP accepts trainees from government agencies, there are considerations that should be taken into account, such as the limited number of trainees that can be accommodated, as well as the cost that would be incurred by the regional agencies just to send participants from provinces to UPD for a minimum of one (1) month. Well-trained researchers, lecturers, and faculty members from local SUCs/HEIs can perform capacity building activities, or at least provide technical assistance especially for those LGUs that are still infant in terms of utilizing RS and GIS as tools for planning and decision-making.

\section{ACKNOWLEDGEMENTS}

This project is made possible with the generous support of the Department of Science and Technology (DOST). The authors are also grateful for the contribution of all who are part of the research team of the PHD Project, as well as personnel from DREAM/Phil-LiDAR 1 and 2 Programs from UPD and collaborating SUCs/HEIs, specifically on their assistance in data gathering, data processing, and field validation activities. The full cooperation of different stakeholders and government agencies during the requirements engineering process and data gathering are as well highly appreciated.

\section{REFERENCES}

DPWH and JICA, 2003. Manual on flood control planning, DPWH Publishing, Manila, Philippines.

Rapinel, S., Hubert-Moy, L., Clement, B., Nabucet, J. and Cudennec, C., 2013. Ditches' network extraction and hydrogeomorphological characterization using LiDAR-derived DTM in wetlands, Hydrology Research, 46, pp. 276-290.

Samarakoon, L., Hazarika, M. and Inomata, Y., 2008. Effective Approach for Capacity Building in GIS and Remote Sensing Technologies in Developing Countries. In: The International Archives of the Photogrammetry, Remote Sensing and Spatial Information Sciences, Beijing, China, Vol. XXXVII, Part B6a, pp. 201-206.

Sharma, M., Paige, G. and Miller, S., 2010. DEM development from ground-based LiDAR data: a method to remove nonsurface objects, Remote Sens., 2, pp. 2629-2642.

United Nations Environment Programme, 2002. Capacity building for sustainable development, UNEP, ISBN: 92-8072266-2. 